\title{
Influence of user characteristics on valuation of ecosystem services in Doñana Natural Protected Area (south-west Spain)
}

\author{
BERTA MARTÍN-LÓPEZ*, CARLOS MONTES AND JAVIER BENAYAS \\ Social-Ecological Systems Laboratory, Department of Ecology, c. Darmin 2, Edificio Biología, Universidad Autónoma de Madrid, \\ 28049 Madrid, Spain
}

Date submitted: 29 September 2006 Date accepted: 1 May 2007 First published online: 7 August 2007

\section{SUMMARY}

Economic valuation of ecosystem services by stated preferences techniques is usually used by policymakers to develop environmental management practices. Critics of the contingent valuation $(\mathrm{CV})$ method have argued that respondents are influenced by several factors, which mean that people do not apply economic motives in responding to $\mathrm{CV}$ questions. This study examines the influence of individuals' environmental behaviour and knowledge about the good concerned on the $\mathrm{CV}$ results and the $\mathrm{CV}$ problem of benefit aggregation in order to determine the extent of the hypothetical market. Here a CV study in the Doñana National and Natural Park (Spain) found that both individual environmental behaviour and knowledge influenced willingness to pay for sustaining specific ecosystem services provided by the biodiversity of Doñana. A distance-decay function was found, which determined the social benefits of the ecosystem services of Doñana. The study illustrates the importance of understanding non-economic motives behind values in order to obtain further information which can support decision-making in environmental management.

Keymords: contingent valuation, ecosystem services, environmental behaviour, geographic distance, local knowledge

\section{INTRODUCTION}

Economic values of ecosystem services (ES) provided by biodiversity are not revealed through observable economic transactions and are therefore not measurable through market data. Environmental valuation techniques can provide useful evidence to support environmental policies by quantifying the economic value associated with the ES provided by biodiversity. For instance, the Millennium Ecosystem Assessment (MEA) recognizes the importance of understanding the economic value of biodiversity for policymaking (MEA 2003). However, the economic valuation of ES in the neo-classical economics framework is a difficult task and it has become the subject of continued controversy and debate over its theoretical basis and moral justification (Horton et al.

\footnotetext{
*Correspondence: Dr Martín-López Tel: +3491497 8008 Fax: +34 914978001 e-mail: berta.martin@uam.es
}

2003). This paper aims to show some problems surrounding the economic valuation of biodiversity.

One method of attempting to capture the benefits of the ES provided by biodiversity is contingent valuation $(\mathrm{CV})$, which measures individual preferences for non-market goods and services by establishing the maximum amount of money that people would be willing to pay (WTP) for improvements in the quality and/or quantity of the ES in question. WTP represents a direct expression of the value of the ES, providing useful estimates in the absence of markets (Mitchell \& Carson 1989).

One of the main principles of this methodology is the concept that individuals' preferences are ranked according to the relative individual desirability. However, there is evidence that a percentage of respondents does not reveal commensurable preferences according to standard economic theory (Rekola et al. 2000) and economic valuation of ES depends on people's underlying motivations (Stevens et al. 1991, 1994; Kotchen \& Reiling 2000).

Different theories of social choice suggest that CV bids usually reflect other motives instead of an economic value. Three different types of motivations can be identified.

(1) Altruistic motives towards future generations and within the current generation, related to the consumer/citizen dichotomy model (Sagoff 1988) where people are motivated by self-interest (consumer) and social interest (citizen). Nyborg (2000) has suggested the terms Homo economicus, referring to those who maximize personal wellbeing, and Homo politicus, referring to those who maximize social welfare.

(2) Recognition of the intrinsic value of non-human species and their environments (Spash \& Hanley 1995). Respondents with egoistic or ethical preferences may be distinguished (Edwards 1986). Egoists are assumed to be motivated by self-interest, while ethicists are assumed to be motivated by 'genuine altruism', which reflects a commitment to the existence of wildlife. Another approach is the rights-based-utilitarian dichotomy, where a rights-based perspective is characterized by beliefs such as 'all species simply have a right to exist'. A utilitarian perspective acknowledges the monetary tradeoffs required to maximize personal or social utility (Kotchen \& Reiling 2000).

(3) Both previous motivations are related to the individuals' moral responsibility, such that $\mathrm{CV}$ respondents derive 
moral satisfaction from the act of contributing to a worthy cause (Kahneman \& Knetsch 1992; Stevens et al. 1994; Spash 1997).

Knowledge about the ES under study can increase the reliability of stated WTP estimates (Paradiso \& Trisorio 2001; Kniivilä 2006), however there is interdependence between environmental attitudes and familiarity with the ES. People who have an intrinsic interest in nature are probably more likely to collect information about it and be more receptive to information about it. Thus, the process of learning depends on the environmental motivations of individuals. Information is filtered, discarded or retained by individuals in accordance with their attitudes and motivations, which of course may not be static themselves (Tisdell et al. 2005).

For certain types of ES, such as those associated with direct use values, it seems reasonable to propose that WTP declines with geographical distance (the distance-decay approach). This effect may exist with respect to services that are related with non-use values (Sutherland \& Walsh 1985; Pate \& Loomis 1997; Loomis 2000; Hanley et al. 2003). There may also be a strong correlation with the familiarity/knowledge variable (Pate \& Loomis 1997). Thus preservation values for water quality depended on available information about the resource and both available information and WTP declined with distance (Sutherland \& Walsh 1985). Individuals tended to be more aware of the ES importance of nearby sites not only because higher access costs made distant sites unattractive, but also because information was more readily available about nearby sites (Johnson et al. 2001).

Mediterranean systems are characterized by their high diversity, closely linked with the unique climate and unpredictability of natural disturbances, but also to the diversification of human uses in adaptation to a highly changeable environment (García Mora et al. 2003). The combination of climate and geological conditions with cultural and historical factors has helped create one of the planet's biodiversity hotspots (Myers et al. 2000). This heterogeneity is expressed in the variability of ES that Mediterranean ecosystems offer. ES can be divided into: provisioning, regulating, cultural and supporting services (MEA 2003). Provisioning services are the products obtained from ecosystems, like food, fuel or timber. Regulating services are the benefits obtained from the regulation of ecosystem processes. Cultural services are the non-material benefits people obtain from ecosystems through spiritual enrichment, cognitive development, reflection, recreation and aesthetic experiences. Supporting services are those necessary for the production of all other ES. In this context, the Doñana social-ecological system (SES) offers a high diversity of ES to human society.

Our aim here is to determine the influence of the noneconomic motives on $\mathrm{CV}$ results, specifically the influences of environmental behaviour and local knowledge. In order to determine the extent of the social benefits of the ES, we examine the impact of the geographic distance between the respondents and the ES under research on the WTP data. The social benefits of the ES depend on the distance-decay function and the concentration of population around the study area (Loomis 2000). In this context, aggregating the WTP across the different zones defined in the distance-decay function seems the most reasonable approach. We provide different aggregation methodologies with the aim of comparing the results and proposing an optimal aggregation technique.

This is the first application of economic valuation where the preferences are studied as a function of environmental behaviour, knowledge and distance in a Mediterranean-type natural protected area.

\section{METHODS}

\section{Study area}

The Doñana Natural Protected Area (NPA) is located in Andalusia on the south-western coast of Spain (Fig. 1), covering $c .2207 \mathrm{~km}^{2}$ of natural systems that include four ecodistricts: aeolian sheets, marshes, coast and the Guadalquivir estuary (Montes et al. 1998). These ecosystems make Doñana unique in many aspects: it is a major stepping-stone in the migration route of birds moving between Europe and Africa, it is home to the most endangered mammal in the world, the Iberian lynx, as well as many endemic, threatened or ecologically interesting species, and it contains perhaps the most significant wetland in Europe (García Novo \& Marín Cabrera 2005).

In 1969, the Spanish government declared Doñana a National Park and its surroundings were declared Natural Park in 1989 by the Andalusian government. Doñana was recognized as an International Biosphere Reserve in 1980, as a Ramsar site in 1982 and as a UNESCO World Heritage Site in 1995. However, despite these conservation efforts, Doñana has serious conservation problems. In recent years, conflicts between conservation and economic development have increased, especially with the expansion of agriculture, urbanization projects and tourism. Four million people visit Doñana NPA annually (Gómez Limón García et al. 2003).

\section{Sampling strategy}

We conducted direct face-to-face interviews at 20 sample points in the Doñana SES. We developed the questionnaire during February-October 2004 and pre-tested it in December 2003 to identify and correct any problems. The representativeness of the final dataset was cross-checked against previous studies about visitors to Doñana (de Lucio \& Múgica 1994; Múgica \& de Lucio 1996; Gómez Limón García et al. 2003). Only adults (>18 years old) were interviewed. We interviewed 672 visitors to the Doñana NPA, but because some of them did not answer all the questions, the final data set was reduced to 663 .

To consider the spatial and temporal variability that characterize Mediterranean ecosystems, the sample population was randomly selected from five different areas 
Figure 1 Study area map. Location of the Doñana SES and its main landscapes.

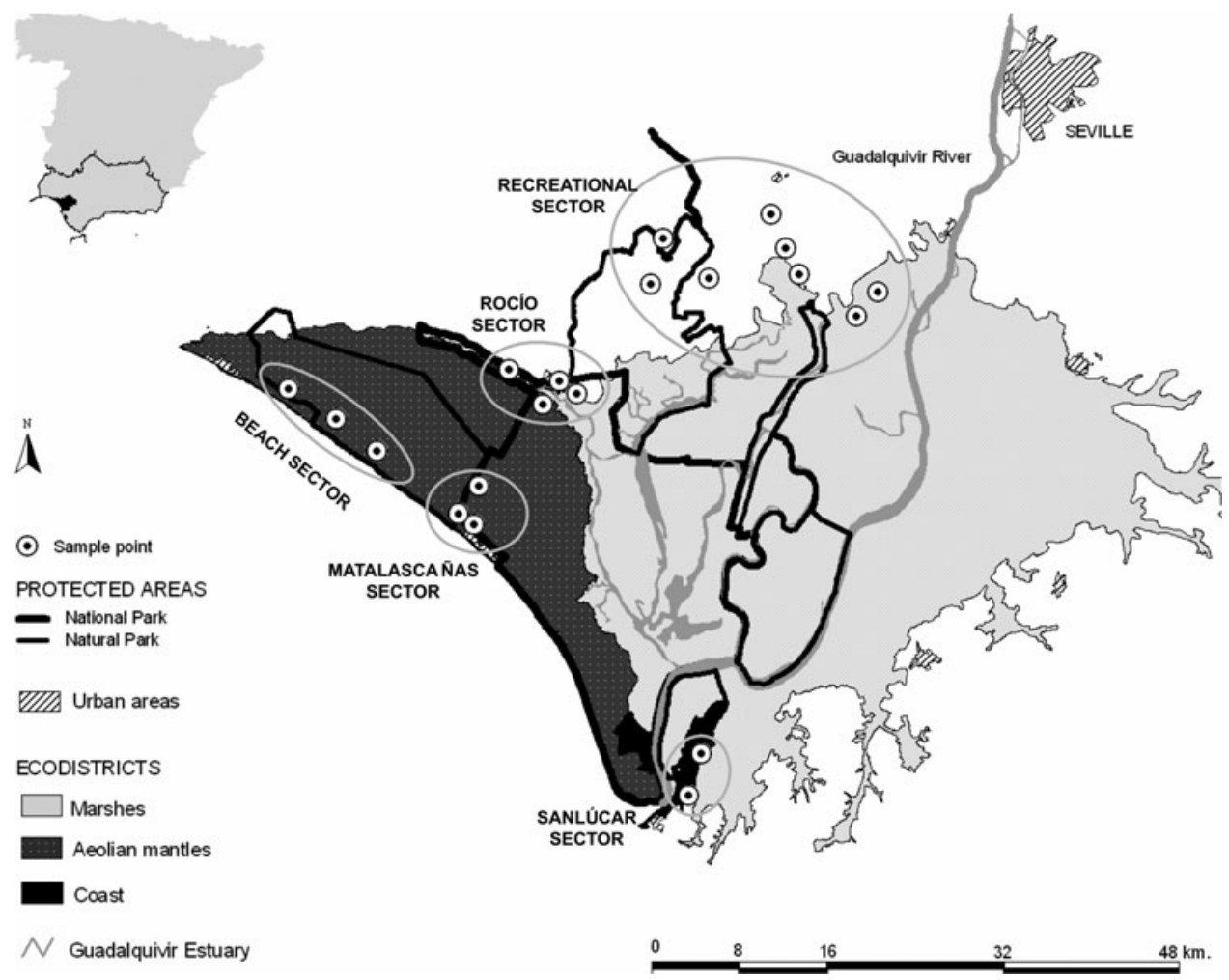

of Doñana SES (Fig. 1) during different months of a homogeneous year, namely (1) the Rocío village sector, (2) the Matalascañas sector, (3) recreational areas, (4) beaches and (5) the Sanlúcar sector. Each of these sectors offers different ES as a result of both sociopolitical and ecological variables, and people make different use of these different sectors.

\section{Structure and content of the questionnaire}

We designed the survey in several sections, which were delivered to respondents in the following order: (1) questions about the importance of Doñana ES, (2) questions regarding WTP for ES, (3) questions to establish knowledge and attitudes, and (4) collection of socioeconomic data and information regarding the characteristics of the respondents' visits to Doñana NPA.

\section{The importance of the ecosystem services}

After a brief explanation of what ES were and the importance of biodiversity in the provision of ES to society, respondents were asked whether they believed that the biodiversity of Doñana NPA provided any ES to society besides tourism. We exclude recreational and tourist services here because several users were looking for these services during their visit to Doñana SES (see B. Martín López, E. Gómez-Baggethun, P.L. Lomas \& C. Montes, unpublished data 2006).

If respondents believed that the biodiversity of Donana provided some ES, we asked which ES they believed to be the most important. The answers were classified as: (1) provisioning services, (2) supporting and regulating services, (3) services derived from an interest in acquiring knowledge, scientific or educational, (4) religious services and (5) spiritual services. The last is reflected in the non-human rights that people attribute to some species, often resulting from an aesthetic experience of wildlife and, therefore, is a consequence of aesthetic services.

\section{Willingness to pay for the ecosystem services}

When respondents identified some ES, in order to establish their maximum WTP we asked: 'If you think that the biodiversity of Doñana NPA provides this ES to society, would you be willing to contribute economically so that the biodiversity of Doñana can continue fulfilling this ES? Your economic contribution would comprise part of an annual donation to a trust fund that would be managed by an environmental organization in order to maintain the ecosystem services'. If the response was affirmative, the elicitation of WTP was an open-ended (OE) format question. If the response was negative, we asked about the motives for their disagreement to pay in order to distinguish protest responses from real zero values.

We used an $\mathrm{OE}$ elicitation format here. Many $\mathrm{CV}$ researchers prefer the closed-ended format because $\mathrm{OE}$ questions are more difficult to answer and the question format is not incentive compatible (Carson et al. 2000), however by using $\mathrm{OE}$ questions we obtained a more realistic and direct measure of maximum WTP without anchoring bias. OE questions may result in lower WTP estimates than closedended format questions (Kiström 1993; Brown et al. 1996), however experimental results comparing hypothetical and 
actual WTP show that the hypothetical bias is lower for the OE format as compared with the closed-ended format (see Balisteri et al. 2001). We used a donation to a trust fund as a payment vehicle to make the hypothetical market more credible and feasible.

\section{Environmental behaviour and knomledge}

Respondents were asked a series of questions to establish their environmental behaviours and what they knew about Doñana. Questions related to the environmental behaviours were classified as either general environmental behaviours or specific behaviours developed towards Doñana NPA. General behaviours toward the environment were measured by traditional variables that are considered indicators of the respondent's interest in nature, such as whether the respondent held membership of an environmental organization and the number of other NPAs that the respondent had visited during the previous year. The Doñana specific environmental behaviours were measured by four variables: (1) the main reason for their visit to Doñana; (2) the activity that the respondent undertook; (3) the amount of time that the respondent spent in his/her visit; and (4) the number of different places that the respondent visited. Familiarity with the Doñana NPA was measured by four indicators, the first two directly related to the respondents' knowledge and the last two to the respondents' perceptions of Doñana. These were: (1) respondents' knowledge of the management of Doñana NPA; (2) respondents' knowledge of the differences among the protection categories and organizations working in Doñana; (3) the main impression that people had when 'Doñana' was mentioned; and (4) the main role that Doñana NPA should play in society. With the aim of classifying Doñana's visitors, these variables were analysed by a twostep clustering technique appropriate for large data sets with mixed variables (Norusis 2003). This enabled continuous and categorical attributes to be derived from a probabilistic model where the distance between two clusters is equivalent to the decrease in the log-likelihood function as a result of merging. The Schwarz Bayesian criterion (BIC) for each cluster within a specified range was used first to initially estimate the number of clusters. This estimate was then refined by finding the largest increase in distance between the two closest clusters at each hierarchical clustering stage. Both background noise and outliers could be identified and screened out.

\section{Socioeconomic and general data}

Social and demographic information included variables such as age, sex, level of study, current occupation, household size and monthly family income. Respondents were also asked about their place of residence in order to estimate how far they had travelled. The survey included general questions, such as the frequency of their visits to Doñana, length of stay, source of information about Doñana NPA and individual satisfaction level attained during the visit.

\section{Economic valuation methodology}

A common feature in the analysis of open-ended CV-bids (Mitchell \& Carson 1989) is that there are a large number of responses with zero WTP. One way to deal with this is to use a censored model, such as the Tobit model. However, if we believe that individuals in the study are more likely to consider first the decision of whether to pay into the fund or not, and then, if participating, how much to pay, the Heckman model (Heckit), wherein 'pay or not' is estimated in the first stage and the positive WTP is estimated in the second stage, is preferable to the Tobit model, which imposes the presumption of censoring (Greene 2000; Sigelman \& Zeng 1999).

Following Sigelman and Zeng (1999), the Heckit model is a response to sample selection bias, which arises when data are available only for cases in which a variable reflecting 'pay', $z^{*}$, exceeds zero.

$$
\begin{aligned}
& z_{i}^{*}=w_{i} \gamma+\mu_{i} \\
& y_{i}^{*}=X_{i} \beta+\mu_{i} \text { observed only if } z_{i}^{*}>0
\end{aligned}
$$

where for the $i$ th individual, $X_{i}$ is a vector of explanatory variables, $\beta$ is a parameter vector common to all individuals and $\mu_{i}$ is a random disturbance term. The error terms are assumed to follow a bivariate normal distribution with means 0 , variances $\sigma_{\mu}=1$ and $\sigma_{\varepsilon}$ and correlation coefficient $\rho$. The observed variable is $z=0$ if $z^{*} \leq 0$ and $z=1$ if $z^{*}>0 ; y=0$ if $z^{*} \leq 0$ and $y=y^{*}$ if $z^{*}>0$. The expected $Y$ is:

$$
E\left(y \mid z^{*}>0\right)=X \beta+\rho \sigma_{\varepsilon} \lambda(-w \gamma)
$$

where $\lambda(-w \gamma)=\frac{\phi(-w \gamma)}{1-\Phi(-w \gamma)}$ is the inverse of the Mill's ratio, $\theta$ is the standard normal density function, and $\Phi$ the standard normal function. Equation (3) implies that the conditional expectation of $y$ is $X \beta$ only when the errors of Eqs (1) and (2) are uncorrelated. In the first stage, we obtained $\gamma$ from a probit estimation of Eq. (1), where $z=1$ if $z^{*}>0$ and 0 otherwise. Pseudo $\mathrm{R}^{2}$ was calculated according to the method proposed by Veall and Zimmermann (1992). In the second stage, we estimated Eq. (3) using ordinary least squares (OLS) regression.

We determined the influence of the non-economic motives on $\mathrm{CV}$ results by two models relative to the central thesis of this study, DISTANCE and USER, estimated by Heckit regression. The DISTANCE model included six categories for the distance variable: (1) $<20 \mathrm{~km}$, (2) $21-50 \mathrm{~km}$, (3) $51-$ $100 \mathrm{~km}$, (4) $101-300 \mathrm{~km}$, (5) 301-700 km and (6) $>701 \mathrm{~km}$. The USER model included six dummy variables to associate every visitor with one user type. Distance and six dummy user variables were used in the first and second stages of the Heckit regression in DISTANCE and USER models, respectively.

We also estimated the first stage of the Heckit model by the following variables: $(a)$ the cost of the respondent's visit to Doñana, $(b)$ the household size and $(c)$ the monthly family 
income, which was a semi-continuous variable that reflected the mid-point of the income intervals used in the questionnaire $(600 €, 1200 €, 1800 €, 2400 €, 3000 €$ and $3600 € ; 1 €=\mathrm{US} \$$ $1.24,2004)$. In order to reduce the heteroskedasticity problem, we have transformed it into its natural $\log$ form. The second stage of the Heckit model included as explanatory variables user's age, household size and monthly family income.

To confirm the results obtained by the USER model, we correlated the WTP amount with environmental-behaviour and knowledge-level factors. The environmental-behaviour factor was constructed by the addition of the following variables: (1) the number of NPAs visited during 2003, in four categories, and (2) whether the visitor held membership of an environmental organization. The knowledge factor was created by adding the following variables: (1) knowledge of Doñana management and (2) knowledge of Doñana's protection status/management.

To obtain further insight into how individuals responded to CV questions, we used the Kaplan-Meier survival function; some recommend this technique for continuous WTP data (see Bateman et al. 2002).

\section{RESULTS}

\section{Users of the Doñana NPA}

The average visitor to Doñana NPA was a 38 -year-old male from Seville $(25 \%)$ or other parts of Spain (30\%), with a university-level education (48\%), an average monthly income of $€ 1770$ and a household of three people. Although the visits were spread throughout the year, visitor numbers peaked May-October. Most visits concentrated on Rocío village and the Visitor Centres of the National Park.

Cluster analysis indicated that a six-cluster solution was the best model because it minimized the BIC value and the change in it between adjacent numbers of clusters (Table 1). The resulting clusters were: (1) environmental professionals of Doñana NPA, (2) users that showed interest in nature (nature users), (3) people who spent one day in Doñana (one-day visitors), (4) visitors who looked for cultural heritage (culture users), (5) people who visited the beach (beach tourists) and (6) pilgrims and religious visitors (Table 2).

\section{Users' perceptions of Doñana ecosystem services}

While biodiversity conservation services were perceived as important by all user categories $(>50 \%$ rated them most important), the perception of other ES varied by user group. Pilgrims did not attach importance to the supportingregulating services; in contrast, religious $(25 \%$ rated them most important) and provisioning (15\% rated them most important) services were considered important. Scientific and educational services were considered important by all categories of user; however $>10 \%$ of environmental professionals rated these as most important.
Table 1 Results of auto-clustering using the Schwarz Bayesian criterion (BIC). BIC changes are from the previous number of clusters in the table, ratios of BIC changes are relative to the change for the two-cluster solution and ratios of distance measures are based on the current number of clusters against the previous number of clusters.

\begin{tabular}{lrcll}
\hline \hline $\begin{array}{l}\text { Number of } \\
\text { clusters }\end{array}$ & BIC & BIC change & $\begin{array}{l}\text { Ratio of BIC } \\
\text { changes }\end{array}$ & $\begin{array}{l}\text { Ratio of } \\
\text { distance } \\
\text { measures }\end{array}$ \\
\hline 1 & 11703.4 & & & \\
2 & 10682.9 & -1020.4 & 1.000 & 1.70 \\
3 & 10200.3 & -482.7 & 0.47 & 1.53 \\
4 & 9983.7 & -216.6 & 0.21 & 1.28 \\
5 & 9804.5 & -179.2 & 0.17 & 1.04 \\
6 & 9767.7 & -36.8 & 0.03 & 1.03 \\
7 & 9786.7 & 10.9 & -0.01 & 1.30 \\
8 & 9793.3 & 16.5 & -0.02 & 1.38 \\
9 & 9831.1 & 57.8 & -0.06 & 1.32 \\
10 & 9943.6 & 112.6 & -0.11 & 1.03 \\
11 & 10060.6 & 116.9 & -0.12 & 1.03 \\
12 & 10183.0 & 122.4 & -0.12 & 1.02 \\
\hline \hline
\end{tabular}

\section{Estimation results}

Respondents refused to participate in $\mathrm{CV}$ procedures because: (1) they conflicted with their beliefs about the role of government in environmental management $(57.2 \%),(2)$ they were opposed to new taxes $(24.7 \%)$, (3) they distrusted government or they thought that government was inefficient $(11.5 \%)$ and (4) individuals with environmental behaviours refused to participate because of the incompatibility between ethical beliefs and ascribing economic value $(6.6 \%)$.

Using the Kaplan-Meier estimator for the respondents that participated in the proposed hypothetical market, the overall annual mean WTP was $€ 23.9$ (median $€ 20$; 95\% confidence limits $€ 21.6-26.2)$.

The chosen explanatory variables and in most cases expected signs were highly significant (Tables 3 and 4). The inverse Mill's ratio (Table 4) indicated some correlation between the error terms in the two steps. Both DISTANCE and USER models explained WTP, validating the data set and indicating the importance of both factors on WTP.

The probit results of DISTANCE (log likelihood= $-346.4, \chi^{2}=49.9$, pseudo- $\left.\mathrm{R}^{2}=0.34\right)$ and USER (log likelihood $=-343.6, \chi^{2}=55.3$, pseudo- $\left.\mathrm{R}^{2}=0.36\right)$ models were consistent with our expectations (Table 3 ). The monthly income variable was positive and significant across both models, and we infer that the probability of users accepting the CV procedure depends on their income. The DISTANCE and USER models showed negative effects on the cost of current use, indicating that individuals were sensitive to the cost of visiting Doñana NPA. People who spent more money in making their visit to the NPA refused to make annual economic contributions to a trust fund in order to conserve the ES provided by Doñana's biodiversity. In the DISTANCE 
Table 2 Characterization of Doñana users by the two-step cluster statistical analysis. Env. Org. = environmental organization; Biod. Cons. = biodiversity conservation; $\mathrm{SD}=$ sustainable development; Econ. Dev. = economic development. The average knowledge of visitor is the result of the addition of 'knowledge about Doñana management' and 'knowledge about Doñana's protection status/management' variables, which are constructed as: $0=$ no knowledge, $1=$ knowledge of some managing institutions and $2=$ extensive knowledge. Several $=4$ and medium $=$ 2-3. The aim of visit was classified in three categories: nature (when visitors demanded activities associated with biodiversity or ecosystems), beach (when visitors spent their time exclusively on the beach) and culture (when visitors were interested in, for example, local traditional practices, folklore or gastronomy). Visit activity was classified as very active when respondents cited activities such as horse-riding, cycling or running, or they actively worked in the Doñana NPA, active when respondents cited activities such as walking, landscape contemplation, bird-watching or organized excursions, and passive when respondents spent their time relaxing or socializing with family and friends.

\begin{tabular}{|c|c|c|c|c|c|c|}
\hline \multirow[t]{2}{*}{ Characteristics } & \multicolumn{6}{|c|}{ Users (\%) } \\
\hline & $\begin{array}{l}\text { Environmental } \\
\text { professionals } \\
(10.3 \%)\end{array}$ & $\begin{array}{l}\text { Nature users } \\
(28.5 \%)\end{array}$ & $\begin{array}{l}\text { One-day visitors } \\
(17.8 \%)\end{array}$ & $\begin{array}{l}\text { Culture users } \\
(16.8 \%)\end{array}$ & $\begin{array}{l}\text { Beach tourists } \\
(11.3 \%)\end{array}$ & $\begin{array}{l}\text { Pilgrims } \\
(14.7 \%)\end{array}$ \\
\hline \multicolumn{7}{|l|}{ Familiarity with } \\
\hline \multicolumn{7}{|l|}{ Doñana NPA } \\
\hline $\begin{array}{l}\text { Associates } \\
\text { Doñana with }\end{array}$ & Nature & Nature & Nature, economy & $\begin{array}{l}\text { Nature, } \\
\text { culture }\end{array}$ & $\begin{array}{l}\text { Nature, } \\
\text { economy }\end{array}$ & $\begin{array}{l}\text { Culture, } \\
\text { economy }\end{array}$ \\
\hline $\begin{array}{l}\text { Main role of } \\
\text { Doñana }\end{array}$ & Biod. Cons., SD & Biod. Cons. & $\begin{array}{l}\text { Biod. Cons., } \\
\text { Econ. Dev. }\end{array}$ & $\begin{array}{l}\text { Biod. Cons., } \\
\text { SD }\end{array}$ & $\begin{array}{l}\text { Biod. Cons., } \\
\text { Econ. Dev. }\end{array}$ & Econ. Dev. \\
\hline $\begin{array}{l}\text { Average } \\
\text { knowledge of } \\
\text { visitor }\end{array}$ & Several & Medium & No knowledge & Medium & No knowledge & No knowledge \\
\hline \multicolumn{7}{|l|}{$\begin{array}{l}\text { Environmental } \\
\text { behaviours }\end{array}$} \\
\hline Aim of visit & Nature & Nature & Nature & Culture & Beach & Culture \\
\hline Visit activity & Very active & $\begin{array}{l}\text { Very active, } \\
\text { active }\end{array}$ & Active, passive & Active & Passive & Passive \\
\hline Hours invested & $168-360$ & $48-360$ & $6-8$ & $48-360$ & $4-8$ & $2-168$ \\
\hline Visited places & $8-20$ & $4-7$ & 1 & $1-4$ & 1 & $1-2$ \\
\hline $\begin{array}{l}\text { Number of } \\
\text { other NPAs } \\
\text { visited }\end{array}$ & $9-12$ & 8 & $1-3$ & $3-5$ & 0 & 0 \\
\hline $\begin{array}{l}\text { Holds } \\
\text { membership } \\
\text { of Env.Org. } \\
(\%)\end{array}$ & 31 & 19 & 7 & 9 & 5 & 0 \\
\hline \multicolumn{7}{|l|}{ Socioeconomic variable } \\
\hline $\begin{array}{l}\text { Visitor's usual } \\
\text { place of } \\
\text { residence }\end{array}$ & $\begin{array}{l}\text { Andalusia, } \\
\text { Spain }\end{array}$ & $\begin{array}{l}\text { Spain, } \\
\text { Europe }\end{array}$ & $\begin{array}{l}\text { Doñana } \\
\text { surroundings, } \\
\text { Huelva, Seville, } \\
\text { Cádiz }\end{array}$ & Spain & Huelva, Seville & $\begin{array}{l}\text { Doñana } \\
\quad \text { surroundings }\end{array}$ \\
\hline
\end{tabular}

model, distance had a positive effect; people who had travelled further to visit Doñana NPA were more likely to participate in the hypothetical market than people who lived nearby. In the USER model, only the dummy variables environmental professionals, nature users, beach users and pilgrims were significant (Table 3).

The second stage of the Heckit model provides additional information about the non-economic motives that influenced WTP (Table 4) in both DISTANCE (log likelihood= -538.9 , adjusted $\left.R^{2}=0.56\right)$ and USER (log likelihood $=$ -522.2 , adjusted $\left.R^{2}=0.56\right)$ models. Monthly income was positive and the only significant socioeconomic variable across both models. The analysis of the open-ended bids also showed a significant distance-decay effect; people who travelled further to visit Doñana were interested in participating in the
CV procedure and willing to contribute lower WTP amounts than locals. The USER model indicates that for environmental professionals and nature users WTP was significantly positive, but for beach tourists and pilgrims WTP was significantly negative.

Mean WTP varied among the categories defined by geographic distance and user group (Table 5).

People with higher levels of environmental behaviour and greater local knowledge were willing to donate more money to maintaining ES than people who were not well informed about the environment of Doñana NPA (Fig. 2). We found a linear relation between WTP and environmental behaviour $\left(y=8.01 x+11.88, R^{2}=0.73\right)$, and local knowledge $\left(y=1.63 x+14.47, R^{2}=0.93\right)$. The users who were willing to pay more money to conserve ES were those who were more 
Table 3 Probit regression results regarding willingness to pay (WTP) or not pay for NPA (first stage of Heckit model). Dependent variable: 0 when $\mathrm{WTP}=0$ and 1 when $\mathrm{WTP}>0 . \quad n=576$. Significance $^{* * *}=1 \%,{ }^{* *}=5 \%$ and ${ }^{*}=10 \%$.

\begin{tabular}{lcrllr}
\hline \hline Variable & \multicolumn{2}{c}{ Distance } & & \multicolumn{2}{c}{ User } \\
\cline { 2 - 3 } \cline { 5 - 6 } & Coefficient & $t$-value & & Coefficient & t-value \\
\hline Constant & $-2.312^{* *}$ & -3.150 & & $-1.641^{*}$ & -1.870 \\
Distance & $0.204^{* * *}$ & 5.008 & & \\
Cost & $-0.201^{*}$ & -1.899 & $-0.145^{*}$ & -1.648 \\
Monthly income & $0.339^{* * *}$ & 3.318 & $0.313^{* * *}$ & 3.046 \\
Household size & -0.047 & -1.197 & -0.049 & -0.738 \\
Environmental & & & $0.322^{* *}$ & 0.765 \\
$\quad$ professionals & & & & \\
Nature users & & & $0.634^{* * *}$ & 1.621 \\
One-day visitors & & & 0.169 & 0.424 \\
Culture users & & & -0.043 & -0.105 \\
Beach tourists & & & $0.219^{*}$ & 0.848 \\
Pilgrims & & & $-0.358^{* *}$ & -0.869 \\
\hline \hline
\end{tabular}

Table 4 Sample selection two-stage least squares regression results (second stage of Heckit model). Dependent variable: $\ln (\mathrm{WTP})$. $n=576$. Significance ${ }^{* * *}=1 \%,{ }^{* *}=5 \%$ and ${ }^{*}=10 \%$.

\begin{tabular}{lcrllr}
\hline \hline Variable & \multicolumn{2}{c}{ Distance } & & \multicolumn{2}{c}{ User } \\
\cline { 2 - 3 } \cline { 5 - 6 } & Coefficient & $t$-value & & Coefficient & t-value \\
\hline Constant & $4.086^{* *}$ & 1.992 & & $-3.342^{*}$ & -1.370 \\
Distance & $-0.237^{* *}$ & -2.096 & & \\
Age & 0.001 & 0.085 & -0.002 & 0.197 \\
Monthly income & $0.482^{*}$ & 1.703 & $0.435^{* *}$ & 1.447 \\
Household size & -0.104 & -0.994 & -0.109 & -1.018 \\
Environmental & & & $0.737^{*}$ & 0.948 \\
$\quad$ professionals & & & & \\
Nature users & & & $0.823^{* *}$ & 1.779 \\
One-day visitors & & & 0.211 & 0.194 \\
Culture users & & & 0.213 & 0.188 \\
Beach tourists & & & $-0.224^{* *}$ & -1.206 \\
Pilgrims & & & $-0.320^{*}$ & -1.274 \\
Inverse Mill's & $5.029^{*}$ & 1.722 & $5.083^{*}$ & 1.854 \\
$\quad$ Ratio & & & & \\
\hline \hline
\end{tabular}

knowledgeable about Doñana and were more active in their environmental behaviour (see Table 2).

Distance also played a role in relation to the type of ES valued (Fig. 3a). WTP for science and education did not follow a distance-decay function, because these services were highly valued at a regional scale. The aesthetic service was the most valued by people who had travelled from places more than $20 \mathrm{~km}$ away. Religious services were the most valued by local people. People who live in Doñana and its surroundings awarded more value to provisioning services than other users.

Religious services followed a distance-decay function because local users (pilgrims and one-day users) assigned greater WTP. Mean WTP by ES and user type (Fig. 3b) provides further empirical evidence of the positive correlation between ethical concern and the WTP amount. However, this positive relationship was only found for science-education,
Table 5 ANOVA tests results for distance $(\mathrm{F}=8.68, \alpha<0.0001)$ and user $(\mathrm{F}=10.28, \alpha<0.0001)$ categories. Standard deviation shown in parentheses. WTP $=$ willingness to pay.

\begin{tabular}{llrc}
\hline \hline Category & & $n$ & Mean WTP \\
\hline Distance & $<20 \mathrm{~km}$ & 63 & $18.23(15.57)$ \\
& $21-50 \mathrm{~km}$ & 33 & $22.37(20.43)$ \\
& $51-100 \mathrm{~km}$ & 189 & $13.09(11.58)$ \\
$101-300 \mathrm{~km}$ & 59 & $11.19(9.31)$ \\
& $301-700 \mathrm{~km}$ & 186 & $9.75(6.59)$ \\
& $>701 \mathrm{~km}$ & 47 & $8.00(3.47)$ \\
User type & Environmental professionals & 52 & $20.16(8.17)$ \\
& Nature users & 175 & $15.03(11.75)$ \\
& One-day visitors & 107 & $11.87(10.78)$ \\
& Culture users & 75 & $14.14(12.88)$ \\
& Beach tourists & 88 & $10.96(9.16)$ \\
& Pilgrims & 67 & $4.46(8.92)$ \\
\hline \hline
\end{tabular}

spiritual-aesthetic and supporting-regulating services. Nature and culture users awarded more value to spiritualaesthetic services and environmental professionals assigned higher WTP to conserving supporting-regulating services. Provisioning services had the opposite trend: users with low levels of environmental behaviour were willing to pay higher amounts than environmentally active users, indicating that perceived utility of certain commodities predominates.

\section{Benefits aggregation}

To assess the total benefit of a public good, it is usual to aggregate mean WTP figures over the relevant market, which in our case was the Doñana SES. This represents an underestimate of benefits, because the ES provided by the biodiversity of Doñana are a national and even a global public amenity. Numerous controversies exist around the aggregation of the economic values of ES. There are several different ways of aggregating annual benefit.

(1) If we assume that non-respondents reflected the general population of Doñana users and assigns them the mean WTP, we obtained $€ 97807858$ (95\% confidence interval: $€ 88395386-107220330)$ as social benefits. This provides the highest social benefits for ES.

(2) If we suppose that protest responses did not reflect the population of Doñana users, social benefits resulted in $€$ 56239518 (95\% confidence interval: € $59827347-61651$ $690)$.

(3) If we suppose that protest responses reflected the most conservative approach by assuming that non-respondents were real zero WTP bids for maintaining ES, social benefits resulted in $€ 45285038$ ( $95 \%$ confidence interval: $€ 40927064-49643013)$.

(4) If we use the results of Heckit regression from DISTANCE model for the whole sample, the social benefits were $€ 51318$ 433; however if we used the means 

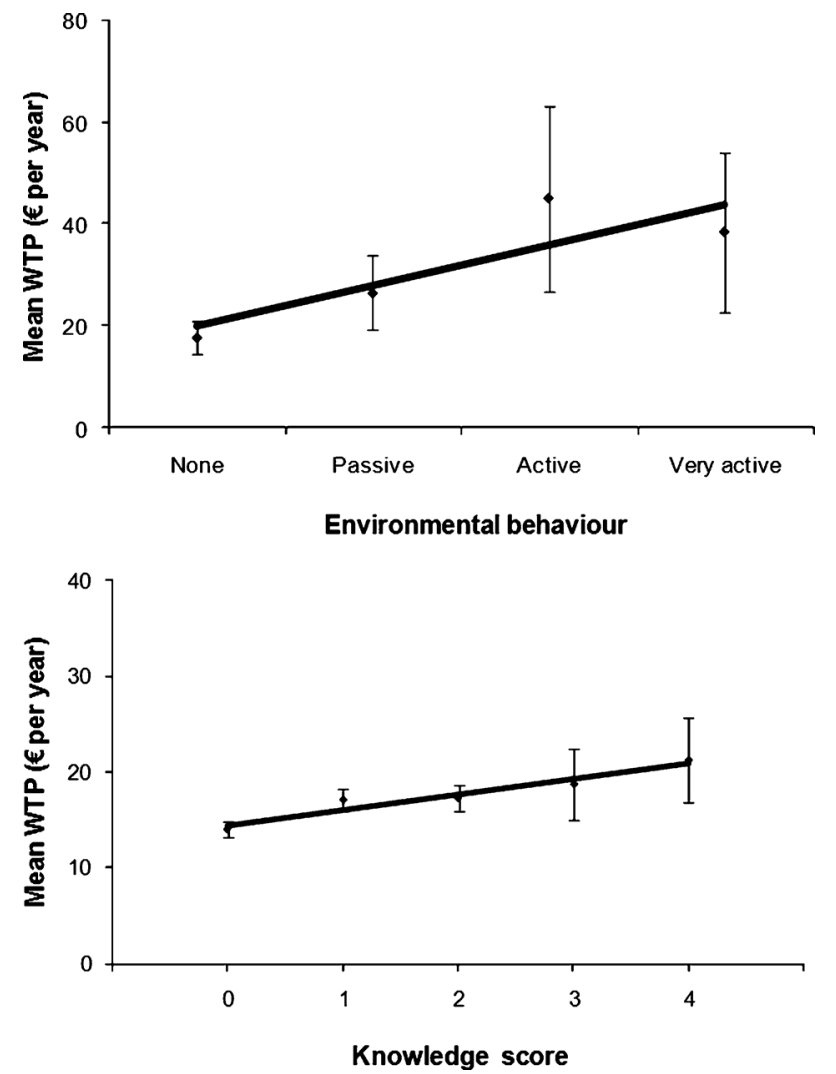

Figure 2 Mean $( \pm \mathrm{SD})$ WTP for conservation of the Doñana ES in relation to $(a)$ user's environmental behaviours; and $(b)$ their local knowledge about Doñana NPA. Environmental behaviours: passive $=>4$ but $<8$ NPAs visited in 2003; active $=>8 \mathrm{NPAs}$ visited in 2003; very active $=>8$ NPAs visited in 2003 and member of an environmental organization. The average knowledge of visitor is the result of the addition of 'knowledge about Doñana management' and 'knowledge about Doñana's protection status/management' variables, where: $0=$ no knowledge; $1=$ knowledge of some managing institutions; 2 = extensive knowledge.

Table 6 Aggregation of annual benefits by Heckit regression estimation of mean WTP for different distances (DISTANCE model). Social benefits $=€ 54974199$.

\begin{tabular}{lllc}
\hline \hline Distance & Mean WTP & Users & Annual benefits (€) \\
\hline$<20 \mathrm{~km}$ & 18.23 & 400510 & 7300857 \\
$21-50 \mathrm{~km}$ & 22.37 & 710159 & 15887323 \\
$51-100 \mathrm{~km}$ & 13.09 & 766350 & 10035400 \\
$101-300 \mathrm{~km}$ & 11.19 & 836887 & 9365752 \\
$301-700 \mathrm{~km}$ & 9.75 & 773523 & 7542583 \\
$>701 \mathrm{~km}$ & 8.00 & 604950 & 4842283 \\
\hline \hline
\end{tabular}

of the sub-samples defined by distance the social benefits increase to $€ 54974199$ (Table 6).

(5) Finally, if we use the results from the USER model, the social benefits were $€ 53732939$ for the whole sample and $€ 52432544$ if we use the mean WTP of user groups (Table 7).
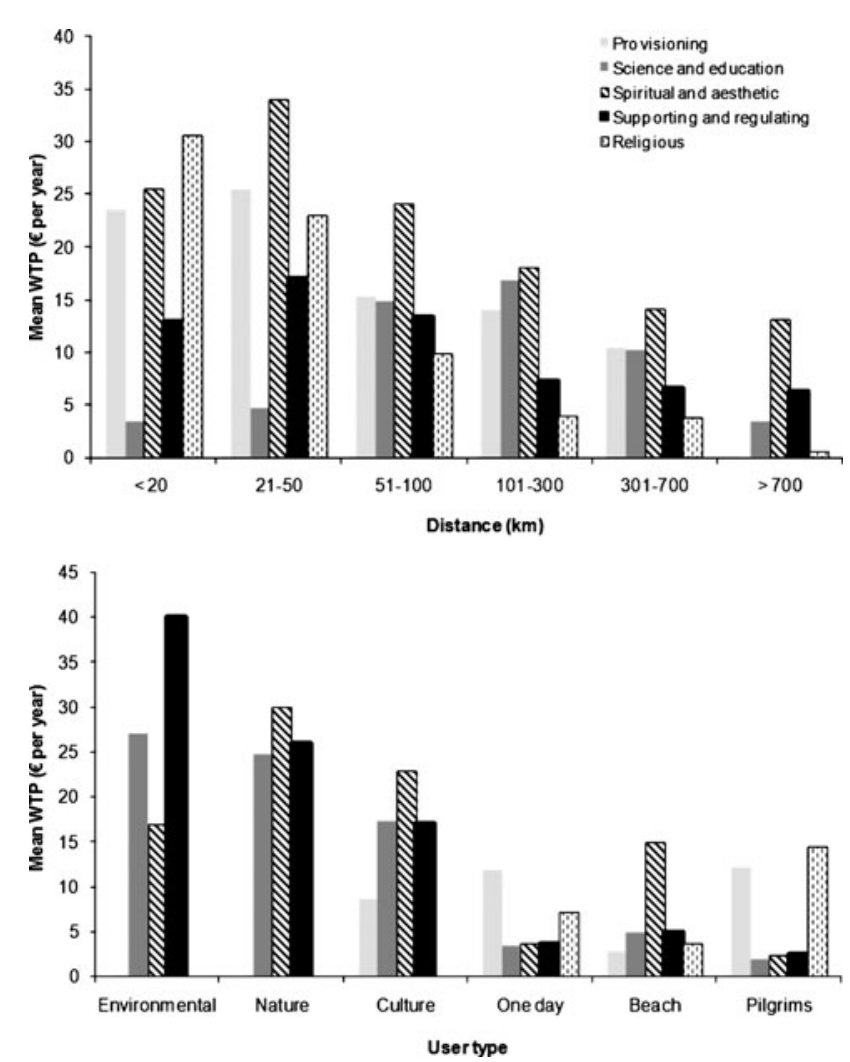

Figure 3 Relationship between WTP for maintaining the Doñana $\mathrm{ES}$ and $(a)$ distance and $(b)$ user type.

Table 7 Aggregation of annual benefits by Heckit regression estimation of mean WTP of user categories (USER model). Social benefits $=€ 52432544$.

\begin{tabular}{llrc}
\hline \hline User type & Mean $\boldsymbol{W T P}$ & \multicolumn{1}{c}{ Users } & Annual benefits $(€)$ \\
\hline Environmental & 20.16 & 421515 & 8497475 \\
Nature users & 15.03 & 1166328 & 17530809 \\
One day visitors & 11.87 & 752998 & 8935468 \\
Cultural users & 14.14 & 687520 & 9719240 \\
Beach tourists & 10.96 & 462439 & 5069513 \\
Pilgrims & 4.46 & 601580 & 2680040 \\
\hline \hline
\end{tabular}

\section{DISCUSSION AND CONCLUSIONS}

Neo-classical economics is accepted as a useful partial valuation when making decisions about ES management, if we assume that human preferences form the basis for the value and if we also assume that aggregate individual preferences reflect social valuation of ES (Pritchard et al. 2000). Valuation of ES was significantly influenced by people's environmental behaviour and knowledge of the ES. Thus, knowledge and environmental behaviour were positively related to WTP; however knowledge exerted more influence than environmental behaviour. This has important implications for environmental policies because it demonstrates the potential impact that environmental education programmes could have on individuals' stated behaviours. In Spanish national parks there is a strong relationship between environmental 
educational programmes and increase in active environmental behaviours (Benayas et al. 1987). Knowledge is positively reinforced by individual experience. On-site use can be considered one of the most effective ways to understand the relative importance of biodiversity (Kniviilä 2006). Excessively restrictive conservation policies, which reduce the user's opportunities to access NPAs, reduce public support and appreciation of ES. In Doñana National Park, restricted access has heightened local opposition toward conservation policies, and local preferences for non-use services have become less important (Elbersen 2001). Although Doñana NPA is one of the most ecologically important and highly controversial areas in Europe, very little attention has been given to users' opinions and preferences (Elbersen 2001). In order to establish successful environmental policies for sustainability of the area, the population of users must be involved and their opinions and preferences, as well as their posture towards the NPA, properly understood.

In the Doñana NPA, we found different perceptions among users about the importance of ecosystem services. While local users prefer cultural and modified ecosystems (Bernáldez 1985) because they are motivated by anthropocentric reasons (provisioning services), others perceive biodiversity conservation services as important, indicating that existence values could play an important role in conservation management decisions (see also Stevens et al. 1991; Kniivilä 2006).

The information obtained using CV techniques can be used to change either environmental behaviours or local knowledge about the natural system.

The value of ES provided by biodiversity is highly dynamic. The factors that control the WTP can increase or decrease over time, and are strongly affected by changes in government policy and other forces, such as media influence. Human values and preferences are not static and pre-existent; rather, they are formed by interaction with nature and society (Pritchard et al. 2000). They evolve as part of social processes.

To express the social valuation of ES by individual preferences, aggregation is one of the most problematic assumptions in CV methodology. Decisions over the size of the benefiting population are crucial in terms of the calculation of the social benefits (Hanley et al. 2003). Previous studies (Loomis 2000; Hanley et al. 2003) tested the distancedecay effect, and therefore we use distance-decay functions as a way of resolving this aggregation problem. Distancedecay relationships may well prove useful in valuation studies because they provide a way to conceptualize the question 'who benefits?' (Hanley et al. 2003). However, we found that the distance-decay functions varied among different ES. For instance, the distance function decayed more rapidly for provisioning and religious services than other non-use values. At a municipal scale, the most important ES were related to religious and provisioning services, whereas at a national or global scale biodiversity conservation became the most important service. Similarly, benefits aggregation obtained from the sub-samples defined by user typology was also useful to define who benefits. We were thus able to better discern which beneficiary group obtained more social benefits from ES. Clearly, the aggregation methods derived from the Heckit regression (methods 4 and 5) provided the most plausible aggregation because they were averages of all methodologies, and the probability of bias originated from the influence of distance decrease. There is a need to consider different scales in $\mathrm{CV}$ to support decision-making processes.

\section{ACKNOWLEDGEMENTS}

We thank Doñana National and Natural Park for providing facilities and the Andalusian Network of Natural Protected Areas for financial support. K. Turner kindly provided instruction in environmental economics. We also thank $\mathrm{P}$. Lomas, E. Gómez, B. Pérez, C. Louit, Á. Sánchez, L. Losada, C. de Miguel and E. Araujo for unselfish help with the interviews, and two anonymous referees for comments that improved this paper.

\section{References}

Balisteri, E., McClelland, G., Poe, G. \& Schulze, W. (2001) Can hypothetical questions reveal true answers? A laboratory comparison of dichotomous choice and open-ended contingent values with auction values. Environmental and Resource Economics 18: 275-292.

Bateman, I.J., Carson, R.T., Day, B., Hanemann, M., Hanley, N., Hett, T., Jones-Lee, M., Loomes, G., Mourato, S., Özdemiroglu, E., Pearce, D.W., Sugden, R. \& Swanson, J. (2002) Economic Valuation with Stated Preference Techniques: a Manual. Northampton, MA, USA: Edward Elgar.

Benayas, J., de Lucio, J.V. \& Bernáldez, F.G. (1987) Environmental attitude shifts as revealed by landscape tastes and activity preferences. The Environmentalist 7: 21-30.

Brown, T., Champ, P., Bishop, R. \& McCollum, D. (1996) Which response format reveals the truth about donations to a public good? Land Economics 72: 152-166.

Carson, R., Groves, T. \& Machina, M. (2000) Incentive and information properties of preference questions. Working Paper, Department of Economics, University of California, California, USA.

de Lucio, J.V. \& Múgica, M. (1994) Landscape preferences and behaviour of visitors to Spanish National Parks. Landscape and Urban Planning 29: 145-160.

Edwards, S.F. (1986) Ethical preferences and the assessment of existence values: does the neoclassical model fit? Northeastern Fournal of Agricultural and Resource Economics 15: 145-150.

Elbersen, B. (2001) Nature on the Doorstep. The Relationship between Protected Natural Areas and Residential Activity in the European Countryside. Utrecht/Wageningen, the Netherlands: Alterra.

García Mora, M.R., Montes, C., Castro, H., Molina, F. \& Baudry, J. (2003) Towards a new ecoregional vision for the management of protected areas in the Mediterranean region. In: Linkages in the Mediterranean Landscape. The Role of Protected Areas in the Territorial Context, ed. M.R. García Mora \& C. Montes, pp.8-25. Sevilla, España: Junta de Andalucía. 
García Novo, F. \& Marín Cabrera, C. (2005) Dońana, Water and Biosphere. Madrid, España: Confederación Hidrográfica del Guadalquivir, Ministerio de Medio Ambiente.

Greene, W.H. (2000) Econometric Analysis, 4th edition. New Jersey, USA: Prentice-Hall International.

Gómez-Limón García, J., Medina Domingo, L., Atance Munoz, I. \& Garrido Palomero, A. (2003) Los visitantes de la comarca de Dońana. Sostenible 4: 1-113.

Hanley, N., Schläpfer, F. \& Spurgeon, J. (2003) Aggregating the benefits of environmental improvements: distance-decay functions for use and non-use values. Fournal of Environmental Management 68: 297-304.

Horton, B., Colarullo, G., Bateman, I.J. \& Peres, C.A. (2003) Evaluating non-user willingness to pay for a large-scale conservation programme in Amazonia: a UK/Italian contingent valuation study. Environmental Conservation 30: 139-146.

Johnson, F.R., Dunford, R.W., Desvouges, W.H. \& Banzhaf, M.R. (2001) Role of knowledge in assessing nonuse values for natural resource damages. Gromth and Change 32: 43-68.

Kahneman, D. \& Knetsch, J.L. (1992) Valuing public goods: the purchase of moral satisfaction. Fournal of Environmental Economics and Management 22: 90-94.

Kniivilä, M. (2006) Users and non-users of conservation areas: are there differences in WTP, motives and the validity of responses in CVM surveys? Ecological Economics 59: 530-539.

Kotchen, M.J. \& Reiling, S.D. (2000) Environmental attitudes, motivations, and contingent valuation of nonuse values: a case study involving endangered species. Ecological Economics 32: 93107.

Kriström, B. (1993) Comparing continuous and discrete contingent valuation questions. Environmental and Resource Economics 3: 6371.

Loomis, J.B. (2000) Vertically summing public good demand curves: an empirical comparison of economic versus political jurisdictions. Land Economics 76: 312-321.

MEA (2003) Ecosystems and Human Well-being. A Framemork for Assessment. Washington, DC, USA: Island Press.

Mitchell, R.C. \& Carson, R.T. (1989) Using Survey to Value Public Goods. The Contingent Valuation Method. Washington, DC, USA: Resources for the Future.

Montes, C., Borja, F., Bravo, M.A. \& Moreira, J.M. (1998) Reconocimiento Biofísico de Espacios Naturales Protegidos. Doñana: Una Aproximación Ecosistémica. Sevilla, España: Consejería de Medio Ambiente, Junta de Andalucía.

Myers, N., Mittermeier, R.A., Mittermeier, C.G., da Fonseca, G.A.B. \& Kent, J. (2000) Biodiversity hotspots for conservation priorities. Nature 403: 853-858.
Múgica, M. \& De Lucio, J.V. (1996) The role of on-site experience on landscape preferences. a case study at Dońana National Park (Spain), Fournal of Environmental Management 47: 229239.

Norusis, M.J. (2003) SPSS 12.0 Statistical Procedures Companion, Upper Saddle River, NJ, USA: Prentice Hall.

Nyborg, K. (2000) Homo Economicus and Homo Politicus: interpretation and aggregation of environmental values. Journal of Economic Behavior and Organization 42: 305322.

Paradiso, M. \& Trisorio, A. (2001) The effect of knowledge on the disparity between hypothetical and real willingness to pay. Applied Economics 33: 1359-1364.

Pate, J. \& Loomis, J. (1997) The effect of distance on willingness to pay values: a case study of wetlands and salmon in California. Ecological Economics 20: 199-207.

Pritchard, L., Folke, C. \& Gunderson, L. (2000) Valuation of ecosystem services in institutional context. Ecosystems 3: 3640.

Rekola, M., Pouta, E., Kuuluvainen, O., Tahvonen, C. \& Li, Z. (2000) Incommensurable preferences in contingent valuation: the case of Natura 2000 Network in Finland. Environmental Conservation 27: 260-268.

Sagoff, M. (1988) The Economics of the Earth. Cambridge, UK: Cambridge University Press.

Sigelman, L. \& Zeng, L. (1999) Analizing censored and sampleselected data with Tobit and Heckit models. Political Analysis 8: 167-182.

Spash, C.L. (1997) Ethics and environmental attitudes with implications for economic valuation. Fournal of Environmental Management 50: 403-416.

Spash, C.L. \& Hanley, N. (1995) Preferences, information and biodiversity preservation. Ecological Economics 12: 191-208.

Stevens, T., Echeverría, J., Glass, R., Hager, T. \& More, T. (1991) Measuring the existence value of wildlife: what do CVM estimates really show? Land Economics 67: 390-400.

Stevens, T., More, T. \& Glass, R. (1994) Interpretation and temporal stability of $\mathrm{CV}$ bids for wildlife existence: a panel study. Land Economics 70: 355-363.

Sutherland, R.J. \& Walsh, R.G. (1985) Effect of distance on the preservation value of water quality. Land Economics 61: 281-291.

Tisdell, C., Wilson, C. \& Swarna Nantha, H. (2005) Policies for saving a rare Australian glider: economics and ecology. Biological Conservation 123: 237-248.

Veall, M.R. \& Zimmermann, K.F. (1992) Pseudo-R ${ }^{2} s$ in the Ordinal Probit model. Fournal of Mathematical Sociology 16: 333342. 